\title{
Taurine reduces the secretion of apolipoprotein B I 00 and lipids in HepG2 cells
}

\author{
Teruyoshi Yanagita*1, Seo-Young Han ${ }^{1,2}$, Ying Hu${ }^{1}$, Koji Nagao', \\ Hideaki Kitajima ${ }^{3}$ and Shigeru Murakami ${ }^{3}$
}

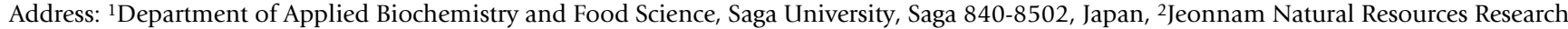 \\ Institute, 756 Kisanri Anyangmyeon Jangheung-gun Jeollanamdo 529-851, Korea and ${ }^{3}$ R\&D Headquarters, Self Medication Business, Taisho \\ Pharmaceutical Co., Ltd., Tokyo 170-8633, Japan \\ Email: Teruyoshi Yanagita* - yanagitt@cc.saga-u.ac.jp; Seo-Young Han - syoung@mail.goo.ne.jp; Ying Hu - yhu@cc.saga-u.ac.jp; \\ Koji Nagao - knagao@cc.saga-u.ac.jp; Hideaki Kitajima - h-kitajima@so.taisho.co.jp; Shigeru Murakami - s-murakami@so.taisho.co.jp \\ * Corresponding author
}

Published: 17 October 2008

Lipids in Health and Disease 2008, 7:38 doi:10.1186/1476-5IIX-7-38

This article is available from: http://www.lipidworld.com/content/7/I/38

(c) 2008 Yanagita et al; licensee BioMed Central Ltd.

This is an Open Access article distributed under the terms of the Creative Commons Attribution License (http://creativecommons.org/licenses/by/2.0), which permits unrestricted use, distribution, and reproduction in any medium, provided the original work is properly cited.
Received: I October 2008

Accepted: 17 October 2008

\begin{abstract}
Background: Higher concentrations of serum lipids and apolipoprotein BI00 (apoB) are major individual risk factors of atherosclerosis and coronary heart disease. Therefore ameliorative effects of food components against the diseases are being paid attention in the affluent countries. The present study was undertaken to investigate the effect of taurine on apoB secretion and lipid metabolism in human liver model HepG2 cells.

Results: The results demonstrated that an addition of taurine to the culture media reduces triacylglycerol (TG)-mass in the cells and the medium. Similarly, cellular cholesterol-mass was decreased. Taurine inhibited the incorporation of $\left[{ }^{14} \mathrm{C}\right]$ oleate into cellular and medium TG, suggesting the inhibition of TG synthesis. In addition, taurine reduced the synthesis of cellular cholesterol ester and its secretion, suggesting the inhibition of acyl-coenzyme A:cholesterol acyltransferase activity. Furthermore, taurine reduced the secretion of apoB, which is a major protein component of very low-density lipoprotein.
\end{abstract}

Conclusion: This is a first report to demonstrate that taurine inhibits the secretion of apoB from HepG2 cells.

\section{Background}

Taurine, $\beta$-sulphonic amino acid was first isolated more than 150 years ago from ox bile [1]. Taurine is considered to be an essential nutrient for human infants and cats and distributed extensively in mammalian cells and tissues $[1,2]$. Its recognized metabolic function in liver is conjugation with bile acids, which is important for bile secretion and lipid digestion [3]. Nevertheless, taurine also has beneficial effects on the liver that include prevention and treatment of cholestasis and prevention of liver damaged due to toxic chemicals [4-6].

In past decades, much attention has been paid to the effects of taurine on bile acid metabolism. Conversely, a few studies concerning the role of taurine on the other liver lipids have been reported. Liver is the central organ of lipid metabolism. Previous in vitro studies with human hepatoblastoma cells showed that cellular levels of tau- 
rine were associated with the rate of bile acid synthesis, the reduction of free cellular cholesterol concentration and the higher expression of low density lipoprotein (LDL) receptor activity [7]. Similarly, in vivo studies have shown that supplementation with taurine influences the serum cholesterol levels in the experimental animals [8]. This was associated with the alterations of activities of $7 \alpha-$ hydroxylase and 3-hydroxy-3-methylglutarylutaryl coenzyme A reductase in the liver [9].

Thus, it appears that taurine involves not only in biliary lipid secretion, but also in cholesterol metabolism in the liver [10]. This possibility is also supported by the previous reports showing taurine-related changes in liver lipid composition of the experimental animals $[11,12]$.

However, even though liver is the central organ of lipid metabolism, only a few studies concerning the effect of taurine on liver lipid metabolism has been reported. In addition, the mechanism for these effects has been not worked out in detail. In addition, there are controversies about the effect of taurine on serum lipid concentrations in human beings $[1,13]$.

Taurine biosynthesis derives from the trans-sulphuration pathway originating with methionine [14]. Liver and serum taurine levels in rats are reported to be approximately $3.62 \mu \mathrm{mol} / \mathrm{g}$ liver, and $2.5 \mu \mathrm{mol} / \mathrm{ml}$ serum, respectively [15].

The liver is the organ to synthesize and secrete the lipoproteins containing apolipoprotein B100 (apoB). ApoB is an essential structural component of very low density lipoprotein (VLDL) and LDL and is required for the intracellular assembly and the secretion of these lipoproteins $[16,17]$. The biological role of VLDL is primarily related to TG transport and eventually to cholesterol transport to the tissues. The synthesis of all these components occur on endoplasmic reticulum (ER) membranes and nascent VLDL particles are assembled from these components before the lipoprotein formation and secretion is accomplished. As the elevation of the concentration of apoB as well as of LDL cholesterol is regarded as an important risk factor for coronary artery disease. It is important to investigate the factors controlling the secretion rate of apoBcontaining lipoprotein by the liver.

The present studies were designed to examine whether taurine alters apoB secretion and lipid metabolism using the human hepatoblastoma cells, HepG 2, as a model of human liver. HepG2 cells have been found to retain many typical functions of the normal human hepatocytes, including lipoprotein and apolipoprotein synthesis [1719].

\section{Results}

Protein content, 3-(4,5-dimethylthiazol-2-yl)-2,5-diphenyl tetrazolium bromide (MTT) cytotoxicactivity and taurine concentration in the cells

As shown in Figure 1, the concentration of cellular taurine was increased in a dose-dependent manner by increasing concentration of taurine added to the medium. No significant changes were noted in the cellular protein content by an addition of $10^{-5}, 10^{-4}$, and $10^{-3} \mathrm{M}$ of taurine under the present culture medium. Taurine did not affect MTT activity, suggesting that taurine has no any cytotoxic effect under the present experimental conditions.

\section{Effect of taurine on triacylglycerol and cholesterol contents in the cells and the medium}

The contents of TG and cholesterol in the cells and the medium were measured. When the cells were precultured in oleate-medium, taurine reduced cellular TG-mass significantly, and reduced the secreted TG (Figure 2). Similarly, cellular cholesterol-mass declined by up to $19 \%$ by taurine (Figure 3).

\section{Effect of taurine on lipid syntheses in the cells}

Figure 4 shows $\left[{ }^{14} \mathrm{C}\right]$ oleic acid uptake by TG and cholesterol ester in the cells and the medium. Taurine inhibited by up to $50 \%$ the incorporation of $\left[{ }^{14} \mathrm{C}\right]$ oleic acid into cellular TG. In addition, taurine reduced the synthesis of

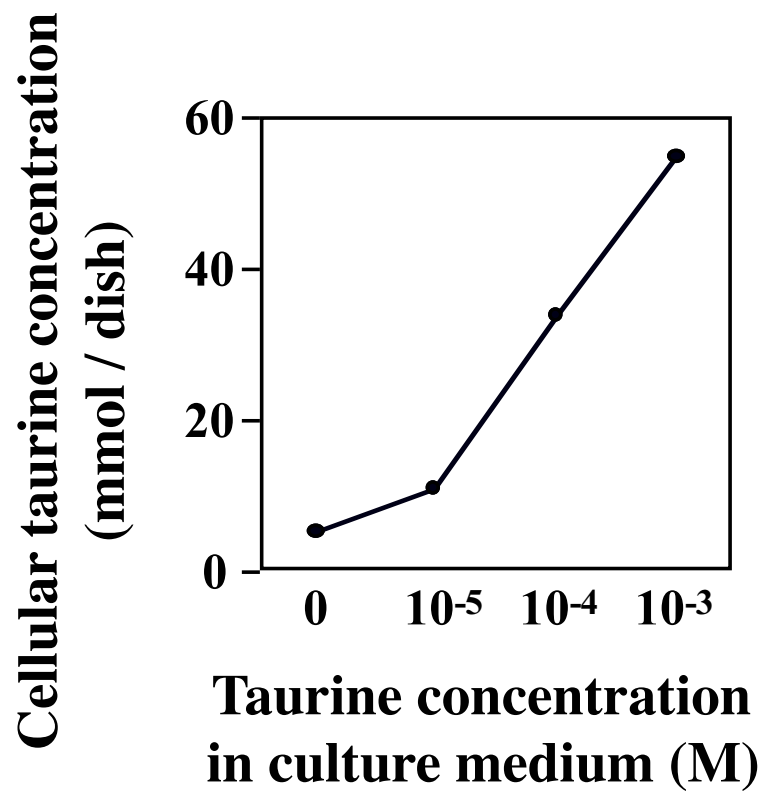

Figure I

HepG2 cells were cultured in the DMEM with or without taurine for $24 \mathbf{~ h r}(\mathbf{n}=3)$. Taurine content was measured by using HPLC method. 

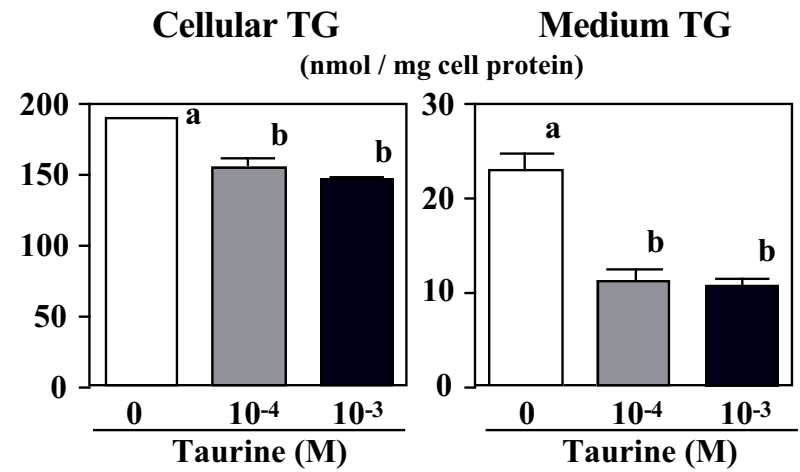

Figure 2

Effect of taurine on TAG-mass in the cells and in the medium. HepG2 cells were cultured in the DMEM with (10${ }^{4}$ or $10^{-3} \mathrm{M}$ ) or without taurine for $24 \mathrm{hr}$. Values are expressed as mean \pm SE $(n=4)$. ${ }^{\text {a, b }}$ Different letters show significant differences at $P<0.05$.

cholesterol ester from $\left[{ }^{14} \mathrm{C}\right]$ oleic acid by $58 \%$ in the cells and reduced its secretion into medium by up to $43 \%$.

\section{Effect of taurine on ApoB secretion to the medium}

Figure 5 shows the effect of taurine on apoB concentrations in the medium after $24 \mathrm{~h}$ incubation. Taurine at the concentrations of $10^{-4}$ and $10^{-3} \mathrm{M}$ reduced apoB secretion by $42 \%$ and $45 \%$, respectively.

\section{Discussion}

ApoB-containing lipoproteins are assembled in the endoplasmic reticulum (ER), with maturation occurring in Golgi apparatus of hepatocytes prior to secretion [20].

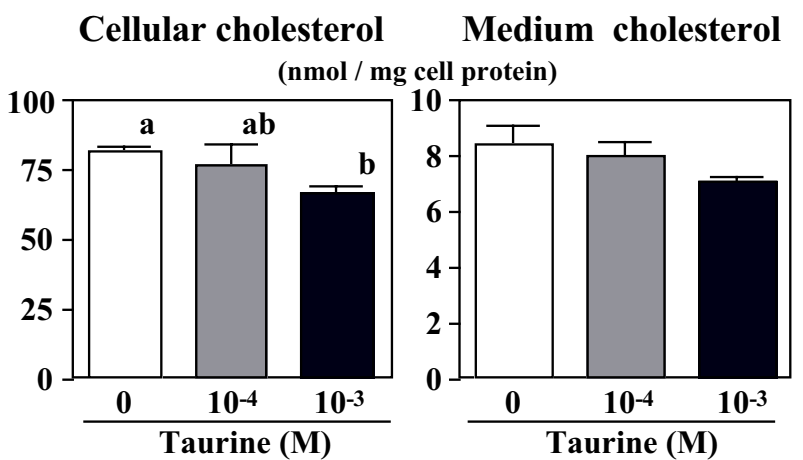

Figure 3

Effect of taurine on cholesterol-mass in the cells and in the medium. HepG 2 cells were cultured in the DMEM with $\left(10^{-4}\right.$ or $\left.10^{-3} \mathrm{M}\right)$ or without taurine for $24 \mathrm{hr}$. Values are expressed as mean \pm SE $(n=4)$. ${ }^{\text {a, b }}$ Different letters show significant differences at $P<0.05$.
ApoB is required for the assembly and secretion of apoBcontaining lipoproteins which transport hydrophobic lipids, cholesterol ester, and TG in their cores. Regulation of the assembly and secretion of apoB-containing lipoproteins has become an active area of investigation as it is recognized that overproduction of apoB-containing lipoproteins may be responsible for coronary artery disease and hyperlipidemia.

The present study focused on examining the effects of taurine on the secretion of TG, cholesterol and apoB from HepG2 cells. Taurine had no affect on MTT activity and cellular protein content in the present cultured condition. Thus, it suggests that an addition of taurine from the concentrations of $10^{-5}$ to $10^{-3} \mathrm{M}$ in the culture medium did not show any cytotoxic effect. When HepG2 cells contains a higher concentration of cellular TG by preincubated with oleic acid-rich medium, taurine remarkably reduced TG-mass (Figure 2) in both the cells and the medium. In the same condition, taurine reduced the incorporation of $\left[{ }^{14} \mathrm{C}\right]$ oleic acid into cellular TG (Figure 1 ), suggesting the inhibition of TG synthesis.

Taurine influenced cholesterol metabolism in HepG2 cells. In condition 1 , taurine $\left(10^{-3} \mathrm{M}\right)$ significantly reduced not only the cellular cholesterol-mass (Figure 3 ) but also the synthesis and secretion of $\left[{ }^{14} \mathrm{C}\right]$ oleoylcholesterol (Figure 4), suggesting the inhibition of cholesterol ester synthesis in the cells. It is well known that cholesterol ester formation is catalyzed by acyl-coenzyme A: cholesterol acyltransferase (ACAT) form free cholesterol and acyl-CoA. Reduction of the synthesis of cholesterol ester may suggest that relatively high amount taurine exerts for ACAT inhibitor.

ApoB is a major protein component of plasma VLDL and LDL. First, the effects of the concentration in the medium on apoB accumulation at the end of the incubation period were determined. We found that taurine inhibits apoB secretion from human hepatocytes preincubated with oleate medium (Figure 5). To determine if changes in intracellular lipid metabolism were responsible for the alteration on apoB secretion, appropriate radiolabeled tracer was added to the medium, the synthesis of cholesterol, cholesterol ester and TG was determined. Because high concentration of apoB has been implicated as risk factor for the development of atherosclerosis, reduction of apoB suggests the beneficial effect of taurine. Results suggest that there is an associated decrease in apoB secretion with a decrease in TG synthesis. Thus, a reduction of TG synthesis may inhibit VLDL-apoB secretion. An important factor determining VLDL-apoB secretion is the size of the intracellular TG pool [20]. Availability of TG for lipoprotein assembly greatly influences the size of VLDL particle secreted by the liver. 

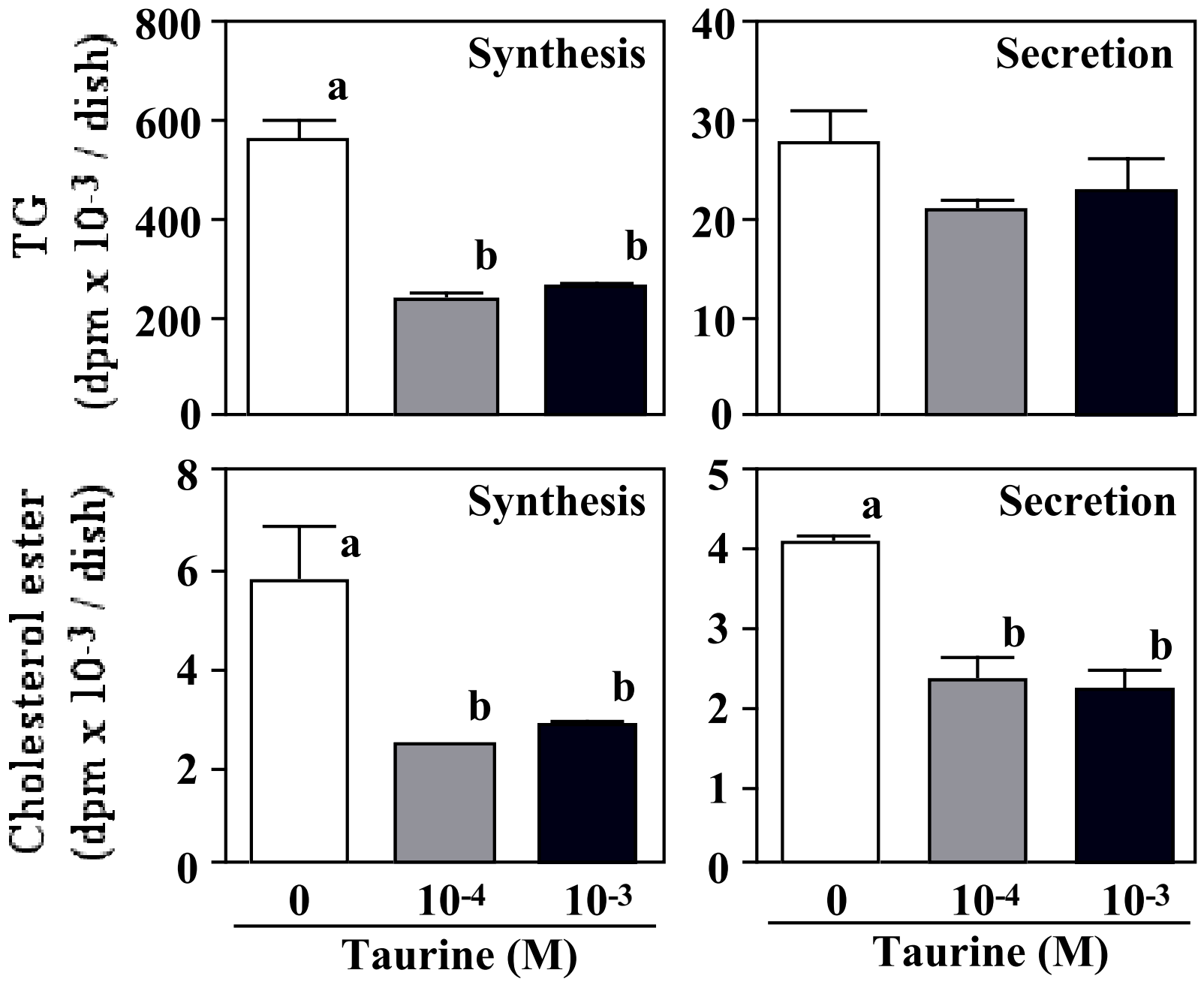

Figure 4

Effect of taurine on the incorporation of $\left[{ }^{14} \mathrm{C}\right]$ oleic acid into cellular TAG and cholesterol-ester and their secretion. HepG2 cells were cultured in the DMEM with $\left(10^{-4}\right.$ or $\left.10^{-3} \mathrm{M}\right)$ or without taurine for $24 \mathrm{hr}$. Values are expressed as mean $\pm S E(n=4)$. a, b Different letters show significant differences at $P<0.05$.

There is evidence to suggest the cholesterol ester can also regulate apoB secretion. Our group [19] and Dashti [21] reported that cholesterol ester synthesis might be a critical element for regulating apoB secretion by hepatocytes. Elevation of the serum cholesterol concentration is known to increase the risk of coronary heart disease. Depressed cholesterol ester formation by taurine may be beneficial for the prevention of such diseases. Recently microsomal triacylglycerol transfer protein (MTP) has been identified as a necessary factor for the assembly of TG-rich lipoproteins $[22,23]$. MTP is localized in the lumen of the endoplasmic reticulum in the liver and intestine, where it transfers TG, cholesterol ester, and phospholipids between phospholi- pid membranes [22,23]. However, effect of taurine on MTP activity remains to be determined.

\section{Conclusion}

Overall, the present study demonstrated that taurine inhibits the secretion of cholesterol ester, TG and apoB in HepG2 cells. The reduction of lipid secretion is partly associated with the inhibition of cellular lipid synthesis. This is the first direct demonstration that taurine inhibits the secretion of apoB in HepG2 cells. 


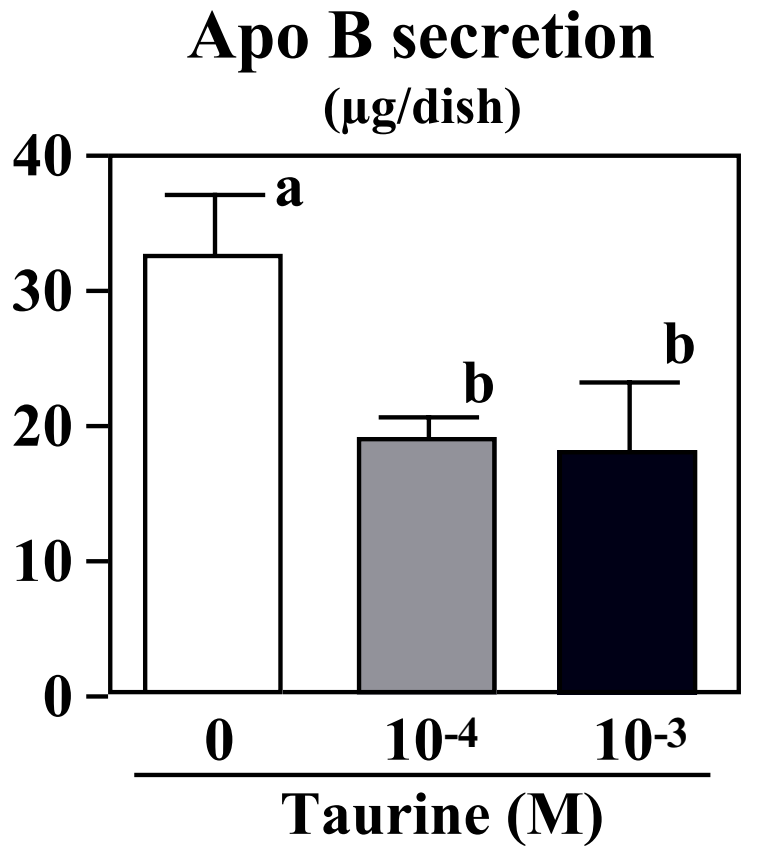

Figure 5

Effect of taurine on apoB secretion into the medium. HepG2 cells were cultured in the DMEM with $\left(10^{-4}\right.$ or $10^{-3}$ M) or without taurine for $24 \mathrm{hr}$. The apoB concentration in the medium was measured by using a sandwich enzymelinked immunosorbent assay. Values are expressed as mean \pm SE $(n=4)$. ${ }^{a}$ b Different letters show significant differences at $P<0.05$.

\section{Methods}

\section{HepG2 cells culture}

HepG2 cells were grown in DMEM supplemented with $10 \% \mathrm{FCS}$, penicillin $(100 \mu \mathrm{g} / \mathrm{ml})$, and streptomycin $(100$ $\mu \mathrm{g} / \mathrm{ml})$ at $37^{\circ} \mathrm{C}$ in an atmosphere containing 95\% air and $5 \% \mathrm{CO}_{2}[19,20]$. The medium was renewed at intervals of 2-3 days. For experiments, a dish $3.5 \mathrm{~cm}$ in diameter and a 24-well plate were used and cells were plated out at a density of $100 \times 10^{4}$ cells/dish or $20 \times 10^{4}$ cells/well. Before the experiment were performed, cells were preincubated in 1\% BSA-DMEM containing $1 \mathrm{mM}$ oleic acid (oleate-medium) for $24 \mathrm{~h}$, then cultured in 1\% BSADMEM with or without (control) taurine (final concentration: $10^{-5}, 10^{-4}$, and $\left.10^{-3} \mathrm{M}\right)$ for $24 \mathrm{~h}(\mathrm{n}=3-4)$. MTT cytotoxicity [24] and protein concentration were determined.

\section{Determination of taurine concentrations in the cells} $100 \mu \mathrm{l}$ of cells and $400 \mu \mathrm{l}$ of $\mathrm{HClO}_{4}(0.2 \mathrm{M})$ were placed into a microtube. After cautious shaking, the mixture was centrifuged (10000 rpm, $3 \mathrm{~min}, 4^{\circ} \mathrm{C}$ ), then $100 \mu \mathrm{l}$ of the supernatant was added to $350 \mu \mathrm{l}$ of methanol and centrifuged again (10000 rpm, furan: methanol: sodium acetate
= 2: 38: 360 (by volume). Taurine concentration was determined by HPLC according to the procedure.

\section{Determination of lipid content and cellular protein}

The cellular protein concentration was determined using Lowry's method [25]. Total lipids in the cells and the medium were extracted and purified using the method of Bligh and Dyer [26]. The contents of TG and cholesterol were determined enzymatically using commercial kits (Wako Pure Chemical Industries, Co., Ltd., Osaka).

\section{Determination of lipids synthesis and their secretion}

To assess the effects of the addition of taurine on the synthesis and secretion of TG and cholesterol ester in HepG2 cells of experiment $1,0.5 \mu \mathrm{Ci}$ of $\left[{ }^{14} \mathrm{C}\right]$ oleic acid was added to each well. The incorporation of radioactivity into lipids and their secretion were measured after $24 \mathrm{~h}$ incubation. Total lipid was extracted as described above. Neutral lipid subclasses were separated by thin-layer chromatography precoated silica gel $\mathrm{G}$ with the solution mixtures petroleum ether: diethylether: acetic acid (80:20:1, by vol.) [27]. The radioactivity was measured with an imaging plate and BAS 2000 (Fuji Photo Film Co. Ltd. Kanagawa). The radioactivity was also measured by liquid scintillation counter (Wallic system 1410, Pharmacia, Uppsala, Sweden). Correction was made for background radioactivity and for quenching by the silica gel.

\section{Determination of $a p \circ B$ secretion into the medium of HepG2 cells}

ApoB was measured by a sandwich enzyme-linked immunosorbent assay [28].

\section{Statistical analysis}

Statistical analysis of data was performed by one-way ANOVA following by Fisher's PLSD test to establish differences among the groups. Differences were considered significant at $\mathrm{P}<0.05$.

\section{List of abbreviations}

ACAT: acyl-coenzyme A cholesterol acyltransferase; ApoB: apolipoprotein B100; ER: endoplasmic reticulum; LDL: low-density lipoprotein; MTP: microsomal triacylglycerol transfer protein; MTT: 3-(4,5-dimethylthiazol-2-yl)-2,5diphenyl tetrazolium bromide; TG: triacylglycerol; VLDL: very low-density lipoprotein.

\section{Competing interests}

The authors declare that they have no competing interests.

\section{Authors' contributions}

TY contributed in planning, analysis and publication of results. SYH contributed in experimental work and analysis. YH contributed in experimental work and analysis. $\mathrm{KN}$ contributed in the planning of the experiment and in 
discussion of results. JF contributed in planning of the experiment and in discussion of results. HK contributed in planning of the experiment and in discussion of results. SM contributed in planning of the experiment, discussion of results, and providing funding for the study.

\section{References}

I. Bouckenooghe T, Remacle C, Reusens B: Is taurine a functional nutrient? Curr Opin Clin Nutr Metab Care 2006, 9:728-733.

2. Yan CC, Masella R, Sun Y, Cantafora A: Transport and function of taurine in mammalian cells and tissues. Acta Toxicol Ther 1991, 1 2:277-298.

3. Chensney RW: Taurine: Its biological role and clinical implications. Adv Pediatr 1985, 32: I-42.

4. Refik Mas M, Comert B, Oncu K, Vural SA, Akay C, Tasci I, Ozkomur E, Serdar M, Mas N, Alcigir G, Yener N: The effect of taurine treatment on oxidative stress in experimental liver fibrosis. Hepatol Res 2004, 28:207-2I5.

5. Nakashima T, Taniko T, Kuriyama K: Therapeutic effect of taurine administration on carbon tetrachloride-induced hepatic injury. Jpn J Pharmacol 1982, 32:583-589.

6. Waterfield CJ, Turton JA, Scales MDC, Timbrell JA: Taurine : A possible urinary marker of liver damage. A study of taurine excretion on carbon tetrachloride-treated rats. Arch Toxicol 1991, 65:548-555.

7. Stephan ZF, Lindsey SL, Hayes KC: Taurine enhances low density lipoprotein binding. J Biol Chem 1987, 262:6069-6073.

8. Tsuji K, Yamanaka Y, Ichikawa M: Effect of taurine on cholesterol gallstione in cholesterol-fed mice. Sufur Amino aci 1983 6:249-255.

9. Bellentani S, Pecorari M, Cordoma P, Marchegiano P, Manenti F, Bosisio E, Defabiani E, Galli G: Taurine increases bile acid poll size and reduces bile saturation index in the hamster. J Lipid Res 1987, 28(9): 1021-1027.

10. Yan CC, Bravo E, Cantafora A: Effect of taurine levels on liver lipid metabolism: an in vivo study in the rat. Proc Soc Exp Biol Med 1993, 202:88-96.

II. Pushpakiran G, Mahalakshmi K, Viswanathan P, Anuradha CV: Taurine prevents ethanol-induced alterations in lipids and ATPases in rat tissues. Pharmacol Rep 2005, 57:578-587.

12. Cantafora A, Blotta I, Rossi SS, Hofmann AF, Sturman JA: Dietary taurine content changes liver lipids in cats. J Nutr 1991, I 2 I( I 0): 1522-1528

13. Tanno N, Oikawa S, Koizumi M, Fujii Y, Hori S, Suzuki N, Sakuma E, Kotake H, Namai K, Toyota T: Effect of taurine administration on serum lipid and biliary lipid composition in man. Tohoku Exp Med 1989, 159:91-99.

14. Hayes KC: Taurine nutrition. Nutr Res Rev 1988, I:99-।/3.

15. Waterfield C], Turtion JA, Scales MDC, Timbrell JA: Taurine, a possible urinary marker of liver damage: a study of taurine excretion on carbon tetrachloride-treated rats. Arch Toxicol 1991, 65:548-555.

16. Olofsson SO, Boren J: Apolipoprotein B: a clinically important apolipoprotein which assembles atherogenic lipoproteins and promotes the development of atherosclerosis. I Intern Med 2005, 258:395-4I0.

17. Dashti N: The effects of low density lipoproreins, cholesterol, and 25-hydroxycholesterol on apolipoprotein B gene expression in HepG2 cells. J Biol Chem 1992, 267:7160-7169.

18. Yanagita T, Yamamoto K, Ishida S, Sonda K, Morito F, Saku K, Saka $\mathrm{T}$ : Effects of simvastatin, a cholesterol synthesis inhibitor, on phosphatidylcholine synthesis in HepG2 cells. Clin Ther 1994, 16:200-208.

19. Yanagita T, Sonda K, Yotsumoto H, Yamamoto K, Murakami S: Effect of ACAT inhibitors, HL-004 and $\mathrm{Cl}-976$, on cholesterol esterification and lipoprotein secretion in HepG2 cells. Curr Thera Res 1994, 57:787-795.

20. Gibbons GF, Wiggins D: Intracellular triacyglycerollipase: its role in the assembly of hepatic very-low-density lipoprotein (VLDL). Adv Enzyme Regul 1995, 35: 179-198.

21. Dashti N, Franklin AF, Abrahamson DR: Effect of ethanolon the synthesis and secretion of apoA-I- and apoB containing lipoproteins in HepG2 cells. J Lipid Res 1996, 37:810-822.
22. Ginsberg HN: Synthesis and secretion of apolipoprotein B from cultured liver cells. Curr Opin Lipidol 1995, 6:275-280.

23. Wetterau JR, Aggerbeck LP, Bouma ME, Eisenberg C, Munck A, Hermier M, Schmitz J, Gay G, Rader DJ, Gregg RE: Absence of micresomal triglyceriglyceride ransfer protein in individuals with abetalipopreteinemis. Science 1992, 258:999-1001.

24. Sladowski D, Steer SJ, Clothier RH, Balls M: An improved MTT assay. J Immunol Methods 1993, I 57:203-207.

25. Lowry OH, Rosebrough NJ, Farr AL, Randall RJ: Protein measure with the Folin reagent. J Biol Chem I95I, 193:265-275.

26. Bligh EG, Dyer WJ: A rapid method of total lipid extraction and purificication. Can J Biochem Physiol 1959, 37:91 I-917.

27. Han SY, Anno T, Yanagita T: S-Propylcysteine reducesapolipoprotein $B 100$ and triacylglycerol secretion in HepG2 cells. Nutrition 2002, 18:505-509.

28. Young SG, Smith RS, Hogle DM, Curtiss LK, Witztum L: Two monoclonal antibody-based enzyme-linked assays of apolipoprotein B. Clin Chem 1986, 32:1484-1490.

Publish with Biomed Central and every scientist can read your work free of charge

"BioMed Central will be the most significant development for disseminating the results of biomedical research in our lifetime. "

Sir Paul Nurse, Cancer Research UK

Your research papers will be:

- available free of charge to the entire biomedical community

- peer reviewed and published immediately upon acceptance

- cited in PubMed and archived on PubMed Central

- yours - you keep the copyright 